\title{
Review of the Fundamentals in Linguistic Landscape Studies in China
}

\author{
Li Yi \\ Xinhua College of Sun Yat-sen University, Dongguan, Guangdong Province, P.R. China
}

Keywords: linguistic landscape; fundamentals; review

\begin{abstract}
This paper offers a brief overview of main theoretical approaches and methodologies in the field of linguistic landscape (LL) studies in China from 2006 to 2017. These are chosen because they are adopted and shared by a majority of LL studies conducted by most of the Chinese scholars in this field, hence they are referred to as the fundamentals of linguistic landscape studies in China. This paper reviews the basic elements that every new entrant to the field of linguistic landscape studies would need to know, the definition of LL, the scope of sampling, the unit of analysis and the categorization scheme. This paper cites parts of the original studies that Chinese scholars tend to follow, and also discusses some possible future directions for LL research.
\end{abstract}

\section{Introduction}

Since the publication of Landry and Bourhis' seminal paper in 1997, research into the linguistic landscape has been enjoying growing interest within sociolinguistics. The corpus of linguistic landscape research already includes a number of locations around the world, e.g. Israeli cities (Ben Rafael et al., 2001), Quebec (Bourhis and Landry, 2002), Tokyo (Backhaus, 2005), Bangkok (Heubner, 2006) and many more, such as Lado (2011), Lai (2012) as cited in Gorter (2013). It's notable that in Wu's 2017 review of the 32 papers of linguistic landscape studies written by Chinese scholars and listed on the CNKI between 2006 and 2015, it can be found that a majority of these papers tend to share some characteristics to a certain extent; and their theoretical and methodological origins for the commonly adopted elements will be shown in the following chapters.

\section{The Definition}

The concept of linguistic landscape, as described by Gorter (2006a: 1) has been used in several different ways. In the literature the concept has frequently been used in a rather general sense for the description and analysis of the language situation in a given country (e.g. for Malta by Sciriha \& Vassallo, 2001), or used for the presence and use of a number of languages in a larger geographic area (e.g. for the Baltic area by Kreslins, 2003). Sometimes the meaning of linguistic landscape might refer to an extended description of the history of languages, or it can include internal language variation in parts of one language, perhaps in relation to its vocabulary and other elements, or even the words used in therapeutic communication (Fleitas, 2003). At times it can indicate the spread and boundaries of dialects (Labov et al., 1997) Nevertheless, the definition given by Landry and Bourhis (1997:25) is followed by all authors in linguistic landscape research:

The language of public road signs, advertising billboards, street name, place names, commercial shop signs, and public signs on government buildings combines to form the linguistic landscape of a given territory, region, or urban agglomeration.

Bourhis and Landry (2002, cited by Gorter 2006a: 2) later added that the notion of linguistic landscape refers to language that is visible in a specified area. Thus Gorter (2006a: 2) perceives that linguistic landscape are concerned with the use of language in its written form in the public sphere (2006a: 2). While Scollon and Scollon (2003) analyze signs, including bilingual signage, in terms of the 'semiotics of place', Sebba (2007) advocates the notion of 'Discourse in Transit', arguing that not only fixed signs may be indicators of multilingual composition of a community, but also 'mobile' and 'non-fixed' public texts (e.g. pamphlets, banknotes, stamps, tickets, handbills, flyers 
etc. (Sebba, 2007:1) should be included in the linguistic landscape approach in general.

\subsection{The scope of sampling}

The relatively rapid development of linguistic landscapes research might be attributed to the technological advances in digital photography, which allows researchers to take an apparently unlimited number of pictures of signs in linguistic landscapes. Although the data collection and computer database construction is relatively uncomplicated, the methodology of this field requires further development. If representatively for a specific area is an important consideration, then where should researchers take pictures and how many?

It would be an inhuman task to take pictures of every public sign on every street, but how could the data from a limited area or city be representative and usable? It should be kept in mind that any data collected should cater for the needs of specific research questions in the first place. Huebner (2006) and Backhaus (2005) limited further their scope for data collection in Bangkok and Tokyo respectively. Huebner's research aimed at exploring the effects of globalization on the multimillion city of Bangkok, thus he and his students gathered quite comprehensive data from eighteen neighborhoods in central as well as suburban Bangkok which, as residents, the students felt would reflect some of the linguistic diversity of the city. Another way of determining the geographic limits of data collection was used by Backhaus, who limited his survey to twenty-eight Yamanote stations in central Tokyo, whose environment provided a multilayered picture of the centre, including business and shopping districts, and less busy sites such as parks and residential areas, for his research question was to study the multilingualism in central Tokyo. For Ben Rafael et al (2001)., their research focus was on the ethnocultural and national divisions in Israeli society, thus it was important to sample localities which represent such distinctions, e.g. Jewish localities, Israeli-Palestinian localities and non-Israeli Palestinian societies. In Sebba's (2007) research, he carried out two case studies which highlighted the notion of 'discourse in transit'. To fulfill that aim, his data collection did not centre on the traditional fixed-signs in linguistic landscapes, but on non-fixed public signs, e.g. pamphlets, banknotes, stamps, tickets, handbills, flyers etc.

\subsection{The unit of analysis}

The linguistic landscape may refer to the linguistic objects which mark public spaces, but what constitutes such an object, or a unit of analysis? An object in linguistic landscape study can include fixed and non-fixed signs, from those which may remain in place for many years to those which may be added or removed on a daily basis. Researchers have different ways of determining what constitutes to a unit of analysis:

[...] A sign was considered to be any piece of written text within a spatially definable frame. The underlying definition is rather broad, including anything from handwritten stickers to huge commercial billboards. Also such items as 'push' and 'pull' stickers at entrance doors, lettered foot mats or botanic explanation plates on trees were considered to be signs. Each sign was counted as one item, irrespective of its size (Backhaus, 2005: 55).

[...] it was decided that in the case of shops and other businesses each establishment but not each sign was the unit of analysis, that is, it was considered 'one single sign' for the analysis (Cenoz and Gorter, 2004: 71).

Cenoz and Gorter's decision is based on the fact that all the signs in one establishment, even if they are in different languages, are the result of the languages used by that company to give an overall impression because each text belongs to a larger whole, a 'house style', instead of being clearly separate. With that mind, they went to great lengths to include in the pictures even very small texts, such as the brand name on the side of a sunshade or a safety-rack, which would hardly be noticed by someone passing by, but these texts were included as part of the establishment as their unit of analysis in that study.

The first definition for the unit of analysis could be the building blocks for the second, especially in the categorization of public signs. It would be painful but not fruitful to analyze each 'sign' separately according to the first definition, as there are usually patterns in the language used within the same establishment, so repetitive analysis of every signs in one company would probably be 
superfluous. Furthermore, analyzing the signs of one establishment as a whole, according to the second definition, can fit instrumentally within the categorization framework of linguistic landscapes. So it is the second definition of unit of analysis that is adopted in this study.

\subsection{The categorization scheme}

Once the data are collected and the unit of analysis is determined, the next step is the coding of public signs according to the categorization schemes. Categorization of the signs is the conventional method in linguistic landscapes study which involves quantitative statistics, with qualitative judgment also possibly being applied at this stage. A sign categorization scheme should include elements such as the number of languages used, the languages on the signs, and the characteristics of bilingual and multilingual signs, e.g. how languages appear on the sign, their respective locations on the sign, the sizes and colours of the fonts used, the order and relative prominence of languages, and whether a text has been translated etc. Ben Rafael et al. developed a sign coding scheme that contains sixteen variables (see Table 1), which has been applied by other researchers such as Cenoz and Gorter.

Table 1. Coding scheme for public signs by Ben Rafael et al (2001)

\begin{tabular}{|c|c|c|}
\hline Official/non-official & Areas & Subareas \\
\hline \multirow{7}{*}{$\begin{array}{l}\text { Top-down signs } \\
\text { (Official) }\end{array}$} & national & \\
\hline & local & \\
\hline & cultural & \\
\hline & educational & \\
\hline & medical & \\
\hline & legal & \\
\hline & social & \\
\hline \multirow{3}{*}{$\begin{array}{l}\text { Bottom-up signs } \\
\text { (non-official) }\end{array}$} & professional & Legal, medical, consulting \\
\hline & commercial & $\begin{array}{l}\text { According to branches, e.g. } \\
\text { food, clothing. Furniture etc. }\end{array}$ \\
\hline & services & $\begin{array}{l}\text { Agencies like real estate, } \\
\text { translation, manpower. }\end{array}$ \\
\hline
\end{tabular}

As reviewed by Gorter (2006a: 3), the dimension of official or governmental versus non-official or non-governmental is common to all articles of linguistic landscape study, since it indicates important language-related differences for the signs placed in linguistic landscapes. While Landry and Bourhis (1997) define 'linguistic landscape' as all the linguistic tokens 'which mark the public space', Heubner (2006) further pointed out that official linguistic tokens, such as artifacts of a central government, are markers of status and power and may reflect the overt language policies of a given state, and commercial linguistic tokens, as posted by individual or local producers, are a manifestation of the covert language policy of a community, and may thus display the 'grass roots' cultural identity and aspirations of its members. Taking official and commercial linguistic tokens together may provide a window on the power relations within the community and evidence for the effects of globalization. A number of findings could derive from comparative studies on official and non-official signs, e.g. Backhaus (2005) discovered that, in Tokyo, official signs are designed mainly to express and reinforce existing power relations, whereas non-official signs make use of foreign languages in order to communicate solidarity with things non-Japanese.

Despite the 'politically inclined' official-commercial division of linguistic tokens, it is necessary for linguistic landscape researchers to arm themselves with 'traditional' linguistic tools in order to analyze the interplay of languages lying deep in multilingual signs. Heubner (2006) designed a table 
(see Table 2) for possible Thai-English combinations, which are based on the script, lexicon and syntax used on the signs.

Table 2. Thai-English mixing - possible types by Heubner (2006, cited in Gorter 2006: 48).

\begin{tabular}{|c|c|c|}
\hline Script & Lexicon & Syntax \\
\hline Thai & Thai & Thai \\
\hline English & English & English \\
\hline Thai & English & English \\
\hline Thai & Thai & English \\
\hline Thai & English & Thai \\
\hline *English & Thai & Thai \\
\hline *English & Thai & English \\
\hline *English & English & Thai \\
\hline
\end{tabular}

Language mixing as shown on the signs may not be as arbitrary as mathematic permutations, so the existence or exclusion of certain language combinations might not only suggest language contact, mixing and change, but also provide evidence for their functions such as reader accessibility and language inequity.

\section{Discussion}

From the review above, we may have an impression that the approaches and methods shared by current Chinese scholars seem to be grounded on the fundamentals of linguistic landscape as reviewed by Western scholars around 2007. While the basic approaches and methodologies seem to remain stagnant in recent years, the descriptive analyses still predominate in China's linguistic landscape studies. In order to further develop the LL studies in China, new perspectives should be introduced, like the emerging field of ecolinguistics may contribute a host of new findings in how linguistic landscapes influence the use of written and spoken languages in people's lives, and also the natural environment surround them. In addition, new technologies should also be wisely used to account for more complex linguistic landscapes in wider geographical regions. As language becomes increasingly digitized, more rigorous research is needed so that it can be replicated by other researchers, and historical changes in LL can also be observed over time.

\section{References}

[1] Backhaus, P. 2005. Multilingualism in Tokyo: a look into the linguistic landscapes. Gorter, D. (ed.) 2006. Linguistic Landscapes: A New Approach to Multilingualism. Clevedon/Buffalo/Toronto: Multilingual Matters.

[2] Ben-Rafael, E. et al. 2001. Linguistic landscapes as symbolic construction of the public space: the case of Israel. Gorter, D. (ed.) 2006. Linguistic Landscape: A New Approach to Multilingualism. Clevedon/Buffalo/Toronto: Multilingual Matters.

[3] Bourhis, R.Y. and Landry, R. 2002. La loi 101 et l'aménagement du paysage linguistique du Québec. In P. Bouchard and R.Y. Bourhis (eds) L’aménagement Linguistique au Québec: 25 D’application de la Charte de la langue Francaise (pp. 107-132). Québec: Publications du Québec.

[4] Cenoz, J. and Gorter, D. 2004. Linguistic landscapes and minority languages. Gorter, D. (ed.) 2006. Linguistic Landscapes: A New Approach to Multilingualism. Clevedon/Buffalo/Toronto: Multilingual Matters.

[5] Fleitas, J. 2003. The power of words: Examining the linguistic landscapes of pediatric nursing. American Journal of Maternal Child Nursing. 28 (6), 384-8.

[6] Gorter, D. 2006a. Introduction: the study of the linguistic landscape as a new approach to multilingualism. In Gorter, D. (ed.) 2006. Linguistic Landscape: A New Approach to 
Multilingualism. Clevedon/Buffalo/Toronto: Multilingual Matters.

[7] Gorter, D. 2013. Linguistic Landscapes in a Multilingual World. Annual Review of Applied Linguistics. 2013, 33,190-212.

[8] Huebner, T. 2006. Bangkok's linguistic landscapess: environmental print, code-mixing and language change. Gorter, D. (ed.) 2006. Linguistic Landscapes: A New Approach to Multilingualism. Clevedon/Buffalo/Toronto: Multilingual Matters.

[9] Kreslins, J. 2003. Linguistic Landscapess in the Baltic. Scandinavian Journal of History 28 (3-4), 165-74.

[10] Labov, W., Ash, S. and Boberg, C. 1997. A National Map of the Regional Dialects of American English. On WWW at www.ling.upenn.edu/phono_atlas/NationalMap/NatioanlMap.html. Accessed 03.04.2017.

[11] Landry, R. and Bourhis, R.Y. 1997. Linguistic landscape and ethnolinguisitc vitality: An empirical study. Journal of Language and Social Psychology 16, 23-49.

[12] Sciriha, L. and Vassallo, M. 2001. Malta: A linguistic landscape. Malta: University of Malta.

[13] Scollon, Ron and Suzie Wong Scollon. 2003. Discourse in place: Language in the Material World. London: Routledge.

[14] Sebba, M. 2007. Discourses in transit. Jaworski, A. and C. Thurlow. (eds.) Semiotics Landscapes and Globalisation: Image, Text, Space. Continuum.

[15] Wu, Xili. 2017. A Critical Review of the Research of Multilingualism in the Linguistic Landscape. Journal of Guangzhou University (Social Science Edition). Aug, 2017, Vol.16, No.8, 78-83. 